\title{
Enjoying Every Moment: Improving Adolescent's Subjective Well-Being Through Adolescent Mindfulness Program
}

\author{
Ardi Primasari ${ }^{1}, K_{w a r t a r i n i}$ Wahyu Yuniarti ${ }^{2}$ \\ 1,2Faculty of Psychology, Universitas Gadjah Mada \\ ${ }^{1}$ Faculty of Psychology, Universitas Mercu Buana Yogyakarta
}

Submitted 30 April 2021 Accepted 16 September $2021 \quad$ Published 30 October 2021

\begin{abstract}
Adolescents often deal with pressures either from the internal or external environment that might trigger psychological issues related to behavior, emotion, academic achievement, and interpersonal relation. Specific intervention is particularly needed to improve adolescents' subjective well-being in such situations. This research aimed at measuring the effectiveness of the Adolescent Mindfulness Program (Program Mindfulness Remaja, known as PRIMA) on adolescent subjective well-being. This research employed an experimental study with a switching replication design. Twenty-eight late adolescents aged 17-21 years-old previously identified with low or moderate subjective well-being participated in the study and received 9 sessions of the Mindfulness Program. Kentucky Inventory Mindfulness Scale (KIMS) was used to measure mindfulness and Satisfaction with Life Scale (SwSL) and Positive Affect \& Negative Affect (PANAS) were used to measure subjective well-being. Results depicted significant improvement in adolescent subjective well-being $(p=0.000 ; p<0.001)$ after the intervention, with a therapeutic effect lasting for more or less than 2 weeks. The result of qualitative analysis indicated that self-compassion meditation was the most meaningful meditation for participants.

Keywords: adolescent; mindfulness; self-compassion; subjective well-being; switching replication
\end{abstract}

Schonert-Reichl and Lawlor (2010) stated that adolescents' subjective well-being is influenced by the emergence of problems concerning behavior, emotion, social experience, academic achievement, and interpersonal relations. Anand and Sharma (2014) discovered that adolescents these days face high pressure from parents and teachers to obtain a good score. Adolescents are also under the pressure to fulfill the requirements to be accepted in a certain school or university and live up to their parents' expectations. A test in an academic institution soon afterward became a traumatic symbol for adolescents and could worsen their anxiety. Diener et al. (2012) found that a person who has a low level of subjective well-being are likelier to be depressive, easily frightened, quicktempered, and having health, friend, and even family problems.

Kirmani et al. (2015) unveiled adolescents with a high level of subjective wellbeing can influence their power of resilience, health behavior (Kalak et al., 2014), mental health (Chervonsky \& Hunt, 2019), and academic achievement (Steinmayr et al., 2018). Subjective well-being is defined as a cognitive and affective evaluation of someone 
regarding life, namely emotional relation toward a particular happening and cognitive judgment toward satisfaction and fulfillment. Savage (2011) mentioned some techniques that had been employed to improve adolescents' subjective well-being such as improving a feeling of gratefulness, building a strong character, developing sources of positive emotion, and finding the meaning of life. In addition, Eryilmaz (2012) discovered that rectifying the relationship between parents and adolescents can improve adolescents' subjective well-being. In addition, the implementation of mindfulness programs for adolescents can improve their subjective well-being (Meiklejohn, 2012).

Subjective well-being is affected by past evaluation, present experience, and future expectations (Durayappah, 2009). Moreover, mindfulness is one of the endeavors to help someone to master the present moment, to let go of the dissatisfying experience, and to develop an open-minded attitude toward the upcoming occurrence. Mindfulness can improve the experience with a positive effect, reduce experience with a negative effect, and improve better competence in responding to a full-of-pressure happening (Kenget al., 2011).

Mindfulness is awareness without judgment on a certain situation, also recognized as non-judgmental awareness. Awareness was a capability to focus on attention from one moment to another moment (Davis \& Hayes, 2011) Awareness is a competence in observing the process of thinking, feeling, and sensing which happened in the now. It requires someone to pay close attention to the body and the mind that is connected in one's authentic experience without resisting or refusing that experience. In addition, mindfulness had a non-judgmental quality, a trait that suggested that someone had to accept the experience as it is with tenderness, kindness, openness, and curiosity (Siegel, 2007). Mindfulness has two important components, namely awareness, and acceptance.

There are two types of mindfulness practice, specifically formal and informal practice. Mindfulness meditation can be done by sitting, lying, standing, or walking with close attention to mind, feelings, body sensation, and sensory experience in every moment. Meanwhile, informal mindfulness practice is to train the awareness in everyday activities such as when taking a bath, walking, eating, or when interacting with other people (Meiklejohn et al., 2012).

Mindfulness is empirically believed to be able to improve positive affect in adolescents, improving adolescent life quality (Galatino et al., 2008), improving psychological well-being (Lawlor et al., 2012; Oberle et al., 2012), and improving optimism (Schoner-Reichl \& Lawlor, 2010). Research conducted by Esch (2013) showed that doing mindfulness meditation can increase dopamine and melatonin, which are hormones that developed positive affect in humans and made them feel comfortable and healthy. Moreover, mindfulness meditation can lessen the negative effect through increasing the norepinephrine hormone, so that the production of hormone that causes stress can be obstructed (Esch, 2013). 
In relation to brain function, Lazar in Baime (2011) revealed that there is an activity change in the insula, a part of the brain that controls the ability to empathize and love, of someone who practices mindfulness meditation. With regards to life satisfaction, mindfulness evidently increases self-acceptance, the capability to feel relaxed and calm dealing with the present moment (Finucane \& Mercer, 2006), and optimism facing the future (Schoner-Reichl \& Lawlor, 2010).

Globally, mental health professionals use mindfulness as an intervention, because mindfulness is practical, able to build mental resilience, and able to maintain emotional health. Mindfulness can be implemented in an individual context or a group context (Wright et al., 2009).

The application of mindfulness in adolescent age groups is less frequent compared to adults (Weare, 2013). However, some studies have explained the effectiveness and visibility of mindfulness treatment in adolescents as a mental health promotion or prevention program. For example, mindfulness is effective to build adolescents' resilience (Greenberg \& Harris, 2012; Huppert \& Johnson, 2010; Zelazo \& Lyons, 2012; Zenner et al., 2014). Participants favored it and confidently accepted the mindfulness intervention. There were no reports that caused a negative side effect. They are able to enjoy and appreciate the mindfulness process and acquired a similar positive effect to the results from the adult group (Weare, 2012). As such, this research intended to understand the effectiveness of the Adolescent Mindfulness Program or Program Mindfulness Remaja (PRIMA) in late adolescents' subjective well-being.

\section{Method}

\section{Participants}

The participants were adolescents who met the following inclusion criteria: 1) adolescents with an age range of 17-21 years-old, 2) having a low or moderate score in subjective wellbeing, and 3) willing to join the research by signing informed consent. Researchers organized identification and selection by distributing the Satisfaction with Life Scale (SwSL) and Positive \& Negative Affect Schedule (PaNAS) to 187 undergraduate students Faculty of Psychology, Gadjah Mada University on September, 2016, with a range of 17-21 years-old. Following the selection process, 28 participants ( 25 females and 3 males) were selected based on the criteria. Of the participants, 25\% were 17 years-old, 65\% were 18 years-old, and $10 \%$ were 19 years-old.

\section{Research instruments}

The level of subjective well-being was measured using Satisfaction with Life Scale (SwSL) that consists of 5 self-evaluation questions. For example "In most ways my life is close to my ideal"; "The conditions of my life are excellent"'; "I am satisfied with my life"; "So far I have 
acquired the important things I want in life"; "If I could live my life over, I would change almost nothing"

Positive \& Negative Affect Schedule (PaNAS) consists of 59 items, adapted and validated by Utami (2009). Respectively, reliability coefficient of life satisfaction subscale had $r=0.749$ whereas positive affect subscale had $r=0.918$ and negative affect subscale $r=$ 0.941 and those three subscales had composite reliability score of 0.9352 .

The level of participants' mindfulness as a manipulation check was gauged using Kentucky Inventory Mindfulness Scale (KIMS) consisting of 39 items, adapted by Putri (2014). The coefficient of KIMS after it had been processed and tested indicated that KIMS had internal consistency categorized as having a high value $(\alpha=0.863)$.

\section{Research design $\mathcal{E}$ implementation}

This research employed a quasi-experiment method using a switching replication design (Figure 1). This design provides strong internal and external validation because the result of the research can be used as a benchmark for generalization. This design also allows all participants to receive similar treatment. As a result, in this quasi-experiment research, this design was ethically the best (Edmonds \& Kennedy, 2013)

The intervention in this study utilized the Adolescent Mindfulness Program (otherwise known as Program Mindfulness Remaja or PRIMA) Modules and workbooks compiled by Primasari (2016). The modules were based on theories, references, and another module developed by Kabat-Zinn in 1990 and Germer in 2009. Adolescent Mindfulness Program Modules consists of breathing meditation, eating meditation, body scan-compassion meditation, self-compassion meditation, forgiveness meditation, gratitude meditation, and loving-kindness meditation. The module consists of 9 sessions: (1) opening, (2) breathing meditation (3) eating meditation (4) body-scan meditation (5) self-compassion meditation (6) forgiveness meditation (7) gratitude meditation (8) loving-kindness meditation (9) closing. Based on the result of the test, PRIMA Modules was significantly able to improve adolescents' mindfulness skills.

This research organized two groups that were an experimental group and a control group with a switching replication design, causing experiment to be carried out two times. For the first experiment, there were 15 participants in the Experiment Group (EG) and 13 participants in the Control Group (CG), and in the second experiment, there were 13 participants in the EG and 14 participants in the CG. The notation of the experiment design could be seen in Figure 1.

\section{Figure 1.}

Switching Replication Design

\begin{tabular}{cccccc}
\hline $\mathbf{N R}$ & $\mathrm{O}_{1}$ & $\mathrm{X}$ & $\mathrm{O}_{2}$ & & $\mathrm{O}_{3}$ \\
\hline $\mathbf{N R}$ & $\mathrm{O}_{1}$ & & $\mathrm{O}_{2}$ & $X$ & $\mathrm{O}_{3}$ \\
\hline
\end{tabular}




\section{Analysis}

The researcher used quantitative and qualitative analyses. Quantitative data analysis was done by adapting covariant analysis developed by Widhiarso (2010). Meanwhile, the qualitative analysis technique used in this research was a descriptive qualitative analysis of the results of observation, interview, and participant daily task book of the participants with three flows activities: data reduction, data display, and conclusion. Qualitative analysis was used to gain a wider understanding of behavior (De Vaus, 2014). In contrast to quantitative research, which uses statistical methods, qualitative research focuses on the exploration of values, meanings, beliefs, thoughts, experiences, and feelings characteristic of the phenomenon under investigation.

\section{Results}

\section{Quantitative analysis result}

Subjective Well-being level between Experimental Group (EG) and Control Group (CG) measured during pretest and posttest and the result were presented in Table 1.

Table 1.

Statistical Description of Subjective Well-being Score

\begin{tabular}{cccccc}
\hline \multicolumn{5}{c}{ First Experiment (Phase 1) } \\
\hline Group & $\mathbf{N}$ & \multicolumn{3}{c}{ Pretest } & \multicolumn{2}{c}{ Posttest } \\
\cline { 3 - 6 } & & Mean & SD & Mean & SD \\
\hline EG & 15 & 14.26 & 12.13 & 35.06 & 17.40 \\
CG & 13 & 44.38 & 30.69 & 34.07 & 24.74 \\
\hline & $\mathbf{5}$ & \multicolumn{5}{c}{ Second Experiment (Phase 2) } \\
\cline { 3 - 6 } Group & $\mathbf{N}$ & Pretest & Posttest \\
& & Mean & SD & Mean & SD \\
\hline EG & 13 & 34.74 & 34.74 & 74.61 & 42.39 \\
CG & 14 & 35.35 & 35.35 & 34.00 & 16.42 \\
\hline
\end{tabular}

Table 1 indicates a difference in the mean score of participants' subjective wellbeing between the Experimental Group (EG) and Control Group (CG) in the first and second experiments. In the first experiment, EG underwent an improvement in the mean score of subjective well-being during pretest and posttest for 20.8 points whereas the CG underwent a decrease in the mean score of subjective well-being during pretest and posttest for 10.31 points.

In the second experiment, EG experienced an improvement in the mean score of subjective well-being during pre-test and post-test for 40.54 points whereas CG experienced a decrease in the mean score of subjective well-being during pre-test and 
post-test for 1.35 points. The change of subjective well-being that happened to EG and CG in the first and second experiments can be seen in Figure 2.

\section{Figure 2.}

The Change in the First and Second Experiment (Phase $1 \mathcal{E}$ 2)

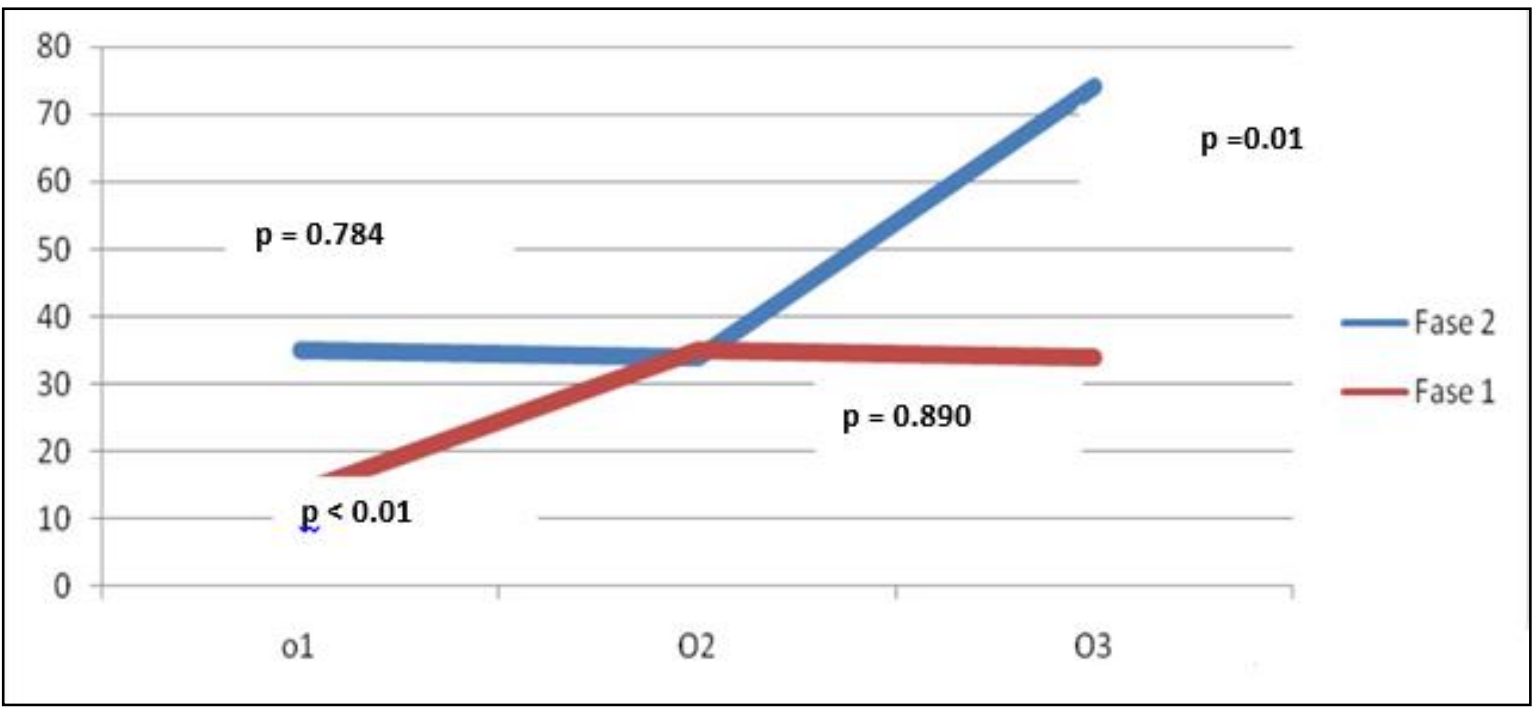

Participants in EG experienced an improvement or a positive change after joining the PRIMA program. It could be seen from the first experiment (phase 1), the Control Group did not undergo a significant change after two weeks following the intervention $(p=0.784 ; p>0.05)$. Therefore, the given intervention for the experimental group in the first experiment (phase 1) could last for about 2 weeks. The result of the analysis showed that there was a significant score difference after intervention between the experimental and control groups, with controlling pre-intervention group score $(F=24.813 ; p<0.01)$.

In the second experiment (phase 2), there was a significant score difference after the intervention between the experimental and control groups by controlling pre-intervention score $(F=26.306 ; p<0.01)$ whereas $C G$ in the second experiment (phase 2), there was no significant difference ( $p=0.890 ; p>0.05)$.

The measurement of manipulation check (KIMS) was done by analyzing the score of both groups before and after the intervention of PRIMA. The test showed $t=-2.831, p=$ $0.004 ; p<0.05$ in the first experiment and $t=-4.469, p=0.000 ; p<0.01$ in the second experiment. Those results gave an idea about the significant difference in KIMS score between EG and CG during the first experiment (phase 1) and the second experiment (phase 2).

Apart from using KIMS as the instrument to check the manipulation or treatment, the researchers also analyzed the assessment toward intervention success indicator. The researcher employed the Intra-Class Correlation Coefficient to discover consistency between raters. The accordance average between raters in the first experiment was 0.959 and 0.960 in the second experiment with the consistency of 0.888 in both groups which 
meant that the accordance between raters was very good or excellent. The accomplishment of the intervention goal was $98.5 \%$ in the first experiment and $99 \%$ in the second experiment. Therefore, the intervention goal had been achieved in each session. Based on those explanations about quantitative analysis above, it could be concluded that the PRIMA program was effective to improve the level of participants' subjective wellbeing.

\section{Qualitative analysis results}

Based on the result of the interview and observation, the difference in condition before and after doing meditation is visible. Before doing this meditation, participants always blamed themselves for who they were, had a mentality of insufficiency, got difficulty in accepting themselves, were rarely thankful for things they had, and were not confident about their physical condition, "I am grateful and accept myself as I am, more confident and love my body more. Every time I want to eat, I always tried to meditate and it's different when I eat with meditation and eat without meditation"

After doing meditation, participants felt more worthwhile and deserved to be happy, more aware of themselves and what they had done until this time, could see and recognize their self -image knew and understand themselves very much, realized selfimperfection, realized their strengths and weaknesses, and realized their condition right then. Participants became more grateful for what they had including their physical condition, their weaknesses, and their experience. Participants accepted their strengths and weaknesses as personal characteristics, became more confident, felt more valuable than they had thought before, were able to think positively about themselves, and believed that everything would turn out well. In addition, participants became happier. From the data, it can be summarized that doing mindfulness meditation can positively influence the participant's physical and psychological health.

\section{Discussion}

In this research, the effect of the PRIMA program can last for about two weeks following the intervention. These research results supported the finding from Carlson et al. (2001) about the effect of mindfulness after the intervention, which lasts for six months in cancer patients. The research conducted by Chien and Thompson (2014) found out that the effect of mindfulness intervention can last until two years following the intervention in schizophrenia patients.

Kabat-Zinn (1990) mentioned that mindfulness breathing can help someone calm their body and mind so that they can see something clearly and with a vast point of view. Moreover, body scan exercises can assist someone in building concentration and attention flexibility at the same time. Those findings are similar to the experience of the PRIMA program, which developed non-judgmental and accepting traits when they did the 
breathing meditation or body scan meditation. Furthermore, doing mindful eating was confirmed to be able to improve positive emotion when they were eating, because they can enjoy eating very much (Smart et al., 2015) and at the same time can lower the stress level (Maillet, 2014).

Forgiveness Meditation was confirmed to lower the anger level and lessen the stress level (Schumacher \& Robert, 2015). Forgiving is recognized to be an effort that could increase satisfaction in making relations (Braithwaite et al., 2011). The explanation before was agreeable to this research's finding. Participants felt better in having relations with other people, particularly with people who had ever hurt them. Participants then viewed others who had hurt them as less negative people.

Gratefulness meditation could be felt by PRIMA program participants as a meditation, which can make someone feel blessed with what they had at that time. Being grateful has a strong connection with psychological well-being. Gratefulness meditation can lessen the negative affect and increase the positive affect. In addition, writing all things that were being thankful for in life was confirmed to be able to increase life satisfaction, lessen life anxiety and increase positive life behaviors (Wood et al., 2010).

Research from Zeng et al. (2015) found out that loving-kindness meditation is confirmed to be effective in increasing positive affect. Kemper et al. (2015) studied the difference between people who did loving-kindness meditation and people who did not do loving-kindness meditation in 21 participants. The results indicated that people who perform loving-kindness meditation have a lower stress level than people who do not perform the meditation. In this research, PRIMA program participants said that lovingkindness meditation made them realize the presence of love from every source such as in best friends, family members, teachers, or other people. Moreover, they understood that they had love and compassion, which could be shared with others or environments.

The fascinating finding in this research related to self-compassion meditation was that this meditation had been considered as the most impressive and meaningful for PRIMA program participants. Neff and Damh (2013) had stated that self-compassion is essential to improve emotional resilience and improve psychological well-being. Doing self-compassion meditation is useful to improve intrapersonal or interpersonal well-being. Through understanding that suffering or bad experience, which occurs in life, is humanistic or is to be a natural happening, it can ease up individuals in facing unintended situations. Individuals are trained to be the best friend of themselves, which develop compassion for themselves as needed when they experience a failure or make a mistake and endure a struggle in life.

After joining Self-Compassion Meditation, participants in this research felt that they were worthy, were able to accept their strengths and weaknesses, believed in the process, and deserved to love. Those findings strengthen another finding of research conducted by Campos et al. (2016), which discovered that self-compassion is a mediating variable between mindfulness and subjective well-being. The individuals' capability to be 
compassionate to themselves and others when facing difficulties in life was confirmed to be significantly able to improve late adolescents' life satisfaction (Anggraeni \& Kurniawan, 2012). Furthermore, the research by Halim (2015) also discovered that there is a significant influence of self-compassion level in late adolescents on subjective wellbeing.

The latest research in Indonesia indicated that self-compassion was significantly able to affect adolescents' subjective well-being. However, a study in Indonesia toward 708 late adolescents, precisely showed that the self-compassion level of Indonesian adolescents was low and the other-compassion level was high (Kartikaputri, 2015). Associating that finding with the collective culture in Indonesia, Markus and Kitayama (1998) stated that culture with an interdependent concept emphasizes the relation with others, the care of others, and the social conformity. Kitayama and Uchida (2003) also stated that a high self-critical level frequently happens in a communal society. Neff and Dahm (2013) mentioned that the truth is, many people have difficulty in loving themselves but face fewer obstacles in loving others. Therefore, when participants underwent a meditation that required them to love themselves, participants could not feel the emotional sensation regarding loving self in their lives.

Some attempts implemented by researchers to improve internal validation in this research were: 1) choosing participants with determined inclusion criteria, who were adolescents, 17-21 years old, and had a low or average level of subjective well-being. They were undergraduates from The Faculty of Psychology at Gajah Mada University and senior high school graduates. It meant that participants were homogeneous. 2) Threatening maturity factor, organized by participants' ethic commitment to keep the confidentiality of the process in the PRIMA program. 3) Eliminating participants who did not attend pretest and posttest from the calculation. 4) Making the condition and the procedure in the first and second experiments similar. And 5) using instruments that met the validation and reliability.

Attempts to improve external validation of the experiment were done with: 1) Employing a single-blind procedure to limit the participants' knowledge about the conducted research variable. 2) Using the experimental design of switching replication to increase external validation because the result supported the process of generalization. Furthermore, that design paid tribute to research ethics because both groups obtained similar interventions.

The research results confirmed that mindfulness programs are effective to improve subjective well-being. In this research, each session in the PRIMA program aimed to improve life satisfaction, improving positive affect and lowering negative affect.

These research results were similar to a study conducted by Hanley et al. (2015), which discovered that someone who did mindfulness meditation had higher subjective well-being than someone who did not do mindfulness meditation. The recent research by Cotton et al. (2016) found out that mindfulness could influence the function of brain 
neurons, which affected insula, thalamus, and lentiform nucleus activities related to the emotional process of adolescents. Moreover, mindfulness and social support could effectively improve adolescents' subjective well-being in which mindfulness became the strongest predictor to improve subjective well-being.

\section{Conclusion}

The research results indicated that Adolescent Mindfulness Program (known as PRIMA) effectively improves adolescents' Subjective Well-being. It can also increase their life satisfaction and their positive affect together with a decrease in negative affect. PRIMA Module was confirmed to be effectively able to improve adolescents' mindfulness skills or competence. The other result was that self-compassion meditation was the most impressive meditation for participants. Participants were able to know, appreciate, and love themselves after doing the meditation.

\section{Suggestion}

Based on the research results and discussions presented before, the researchers had some suggestions for the betterment and those were as follows: 1) Participants had to practice and apply mindfulness in daily activities to get maximum benefit. 2) For the next researchers, it is suggested that they conduct a replication of this study for different age groups, which were children and adult groups. 3) Experts could apply this program (PRIMA) to adolescents and could be used as one of the interventions that improve subjective well-being and mental health.

\section{Acknowledgement}

I would like to acknowledge the efforts made by Prof. Kwartarini Wahyu Yuniarti, M.Med.Sc., PhD., Psikolog; Dr. Muhana Sofiati Utami, M.S., Psikolog; Dr. Bhina Patria, rer.pol., M.A., in giving me their expert comments and advice on this paper.

\section{Authors' Contribution}

Clara Lukitasari Wibowo, Vincent Edi Hartono, Alifa Syamanta, Pramundika Tungga Dewi, Arini Pinondang Pandiangan

\section{Conflict of Interest}

The authors have no conflict of interest to disclose.

\section{Funding}

This work was funded by Prof. Kwartarini Wahyu Yuniarti and Ardi Primasari. 


\section{References}

Anggraeni, D. T., \& Kurniawa, I. N. (2012). Self compassion and satisfaction with life: A prelimenary study on Indonesia college students. International Proceedings of Economics Development and Research, 53, 105-108.

Anand, U., \& Sharma, M. P. (2014). Effectiveness of a mindfulness based reduction program on stress and well being in adolescent in a school setting. Indian Journal of Positive Psychology, 5(1), 17-22.

Baime, M. (2011) This is your brain on mindfulness. Sambala Sun, 45-84 Retrieved from https://www.nmr.mgh.harvard.edu/ britta/SUN_July11_Baime.pdf+\&cd=1\&hl=en $\& c t=c l n k \& c l i e n t=$ firefox-b-ab

Beauchemin, J., Hutchins, T. L., \& Paterson, F. (2008). Mindfulness meditation may lessen anxiety, promote social skill, and improve academic performance among adolescent with learning dis abilities. Complementary Health Practice Review, 13, 3445

Biegel, G. M., Brown, K. W., Shapiro, S. I., \& Schubert, C. M. (2009). Mindfulness based stress reduction for the treatment of adolescent psychiatric outparients: A randomized clinical trial. Journal of Consulting and Clinical Psychology, 17, 885-866.

Braithwaite, S., Selby, E., \& Fincham, F. D. (2011). Forgiveness and relationship satisfaction: Mediating mechanisms. Journal of Family Psychology, 25, 551-559.

Bogel, S. M., Lehtonen, A., \& Restifo, K. (2010). Mindful parenting in mental health care. Mindfulness, 1(2),107-10. https://doi.10.1007/s1267101000145

Campos, D., Cebolla, A., Quero, S.,...,Banos, R. M. (2016). Meditation \& happiness: Mindfulness and self compassion may mediate the meditation of happiness relationship. Journal of Personality and Individual Differences, 93(2), 80-85.

Carlson, L. E., Ursuliak, Z., Goodey, E., Angen, M., \& Speca, M. (2011). The effect of a mindfulness meditation based stress reduction programm mood and symptoms of stress in cancer outpatients: 6 month follow up. Support Care Cancer, 9(2), 112-123

Chien, W. T., \& Thompson, D. R. (2014). Effcet of a mindfulness-based psychoeducation programme for chinese patient with schizophrenia: 2-year follow up. The British Journal of Psychiatry, 205(1), 52-59

Chervonsky, E., \& Hunt, C. (2019). Emotion regulation, mental health, and social wellbeing in a young adolescent sample: A concurrent and longitudinal investigation. Emotion, 19, 270-282

Davis, D. M \& Hayes, J. A (2011) What are the benefits of mindfulness? A practice review of psychotherapy-related research. Psychotherapy, 48 (2), 198 -208

De Vaus, D. A. (2014). Surveys in Social Research. (6th ed). UCL Press

Diener, E., Tay, L., \& Ronald, I. (2012). Theory and validity of life satisfaction scale. Social Indicators Research, 112(3), 497-527. https://doi.10.1007/s11205-012-0076-y 
Cotton, S., Luberto, C. M., Sears, R. W., Strawn, J. R., Stahl, L., Wasson, R. S., et al. (2016). Mindfulness-based cognitive therapy for youth with anxiety disorders at risk for bipolar disorder: a pilot trial. Early Intervention in Psychiatry, 10, 426-434. https://doi.org/10.1111/eip.12216

Duryappah, A. (2010). The 3p model: A general theory of subjective well being. Journal of Happiness Study, 1-36. https://doi.org/10.1007/s10902-010-9223-9.

Edmonds, W. A., \& Kennedy, T. D. (2012). An applied reference guide to research designs: Quantitative, qualitative, and mixed methods. Sage.

Esch, Tobias. (2013). The neurobiology of meditation and mindfulness. In S. Schmidt \& H. Walach (Eds.), Meditation - Neuroscientific Approaches and Philosophical Implications (pp. 153-173) https://doi.org/10.1007/978-3-319-01634-4_9

Eryilmaz, A. (2012). How do adolescent increased their subjective well-being by means of establishing relationships with their parents? Journal of Psychiatry and Neurological Sciences, 11, 21-30. https://doi.10.5350/DAJPN2012250308

Finucane, A \& Mercer, S. W. (2006). An exploratory mixed methods study of the acceptability and effectiveness of mindfulness -based cognitive therapy for patients with active depression and anxiety in primary care. BMC Psychiatry, 6(14), 6-14. https://doi.10.1186/1471-244X-6- 14

Galantino, M., Galbavy, R., \& Quinn, L. (2008). Therapeutic effects of yoga for children: A systematic review of the literature. Pediatric Physical Therapy, 20(1), 66-80.

Germer, C. K. (2009). The mindful path to self-compassion. Guilford Press.

Greenberg, M. T \& Harris, A. R. (2012) Nurturing mindfulness in children and youth: Current state of research. Child Development Perspectives, 6(20),161-166.

Halim, A. R (2015). Pengaruh self compassion terhadap subjective well-being pada mahasiswa luar Jawa tahun pertama Universitas Negeri Semarang. (Unpubish Thesis). Faculty of Psychology, Universitas Negeri Semarang

Hanley, A., Warner, A. \& Garland, E. L. (2015). Associations between mindfulness, psychological well-being and subjective well-being with respect to contemplative practice. Journal of Happiness Study, 6, 14-23.

Huppert, F. A., \& Johnson, D. M. (2010). A controlled trial of mindfulness training in schools: The importance of practice for an impact on well-being. The Journal of Positive Psychology, 5(4), 264-274. https://doi.org/10.1080/17439761003794148

Kalak, N., Lemola, S., Brand, S., Holsboer-Trachsler, E., \& Grob, A. (2014). Sleep duration and subjective psychological well-being in adolescence: A longitudinal study in Switzerland and Norway. Neuropsychiatric Disease and Treatment, 10, 1199-1207.

Kartikaputri, Deri Anggita (2015) Studi deskriptif mengenai derajat self-compassion pada mahasiswa psikologi Universitas Kristen Maranatha. (Unpublished thesis). Universitas Kristen Maranatha

Kabat-Zinn, J (1990). Full catastrophe living. Dell Publishing

Kemper K. J., Powell, D., Helms, C. C., \& Kim-Shapiro, D. B. (2015). Loving kindness 
meditation's effects on nitric oxide and perceived well-being: A pilot study in experienced and inexperienced meditators. Explore, 11, 32-39.

Keng, L. S., Smoski, M. J., Robins, C. J. (2011). Effect of mindfulness on psychological health: A review of empirical studies. Clinical Psychological Review, 31(6), 1041-1056. https://doi.org/10.1016/j.cpr2011.04.006

Kirmani, M. N., Sharma, P., Anas, M \& Sanam, R (2015). Hope, resilience, and subjective well being among college going adolescent girls. International Journal of Humanities $\mathcal{E}$ Social Science, 2(1), 262-270.

Kitayama, S., \& Uchida, Y. (2003) Explicit self-critism and implicit self-regard in two cultures. Journal of Experimental Social Psychology, 39, 476-482.

Markus, H. R., \& Kitayama, S. (1998). The cultural psychology of personality. Journal of Cross-Cultural Psychology, 29, 32-61.

Meiklejohn, J., Phillips, C., Freedman, M.L., Griffin, M.L., Biegel, G., Roach, A., Frank, ..., Saltzman, A. (2012). Integrating mindfulness training into K-12 education: Fostering the resilience of teacher and students. Mindfulness, 3, 291 https://doi.org/10.1007/s12671-012-00945

Maillet, Myles A. (2014). The effectiveness of mindful eating in a student population. (Undergraduate Honors Theses. 7. Retrieved from https://ir.lib.uwo.ca/psychK_uht/7

Neff, K. D., \& Dahm, K. A. (2013). Self-Compassion: What it is, what it does, and how it relates to mindfulness. In M. Robinson, B. Meier \& B. Ostafin (Eds.) Mindfulness and self- regulation. Springer.

Oberle, E., Schonert-reichl, K.A., Lawlor, M. S., \& Thomson, K. C. (2012). Mindfulness and inhibitory control in early adolescence. Journal of Early Adolescent, 32(94), 565-588.

Primasari, Ardi (2016) Modul PRIMA: Program Mindfulness Remaja. Unpublished manuscript.

Putri, F. A. S. (2014). Peran mindfulness dalam memediasi hubungan antar kelekatan ibu dengan rejection sensitivity pada remaja. Unpublished manuscript.

Savage, J. A (2011). Increasing adolescent's subjective well-being: Effects of a positive psychology intervention in comparison to the effect of therapeutic alliance, youth factors, and expectancy for change. Unpublished manuscript.

Schonert-Reichl, K. A \& Lawlor, M. S. (2010). The effect of a mindfulness-based education program on pre and early adolescent's well being \& social emotional competence. Mindfulness, 1(3),137-151. https://doi.org/10.1007/s12671-010-00118

Siegel, D. J. (2007). The mindful brain: Reflection and attunement in the cultivation of wellbeing. Norton.

Schumacher, Matthew Robert. (2015). Anger, forgiveness and mindfulness: Correlates of perceived stress in an LGB sample. UNT Digital Library. http://digital.library.unt.edu/ark:/67531/metadc822763/. Accessed December 14, 2016. 
Steinmayr, R., Heyder, A., Naumburg, C., Michels, J., Wirthwein, L. (2018). School-related and individual predictors of subjective well-being and academic achievement. Frontiers in Psychology, 9, 2631.

Smart, R., Chisum, A., Robertson-Pfeffer, K, Tsong, Y. (2015). Women's experience with a mindful eating course on a university campus: A pilot study. Californian Journal of Health Promotion, 13(1), 59-65.

Utami, M. S. (2009). Keterlibatan dalam kegiatan dan kesejahteraan subjektif mahasiswa. Jurnal Psikologi, 36(2), 144-163.

Weare, K (2013). Developing mindfulness with children and young people: A review of the evidence and policy context. Journal of Children's Services, 8(2), $141-153$.

Widhiarso, W. (2010). Aplikasi Anava campuran untuk desain eksperimen pre-testdesign. Fakultas Psikologi Universitas Gadjah Mada.

Wright, S., Day, A \& Howells, K. (2009). Mindfulness and the treatment of anger problems. Aggression and Violent Behaviour, 14(5), 396-401

Wood, A. M., Fro g, J.J \& G e r a th y, A (2010). Gratitude and well-being: A review and theoretical integration. Clinical Psychology Review, 30(7), 890-905. https://doi.org/10.1016/j.cpr.2010.03.005.

Zenner, C., Herrnleben-Kurz, S. \& Walach, H. (2014). Mindfulness-based interventions in schools - a systematic review and meta-analysis. Frontiers in Pyschology, 5(1), 1-20

Zelazo, P. D \& Lyons, K. E. (2012). The potential benefits of mindfulness training in early childhood: A development social cognitive neuroscience perspective. Child development Perspectives, 6(2), 154-160.

Zeng, X., Chiu, C. P. K., Wang, R., Oei, T. P. S., \& Leung, F. Y. K. (2015). The effect of loving-kindness meditation on positive emotions: a meta-analytic review. Frontiers in Psychology, 6, 1693. http://doi.org/10.3389/fpsyg.2015.01693 